$$
\begin{array}{cccc}
\text { S sciendo } & \text { International Conference KNOWLEDGE-BASED ORGANIZATION } \\
\text { Vol. XXVI } & \text { No } 3 & 2020
\end{array}
$$

\title{
MODERN TECHOLOGIES IN COMPUTER DESIGN AND APPLICATION OF SYSTEMS FOR STRESS-STRAIN CALCULATIONS OF WEAPON SYSTEM ELEMENTS
}

\author{
Stamen Iliev ANTONOV \\ "Vasil Levski" National Military University, Veliko Tarnovo, Bulgaria \\ stamantonov@abv.bg
}

\begin{abstract}
The article explores contemporary computer tools for calculating stress-strain of mechanisms and elements for heavy weapons and machine guns. The article is intended to aid the knowledge and skills requirements in the future work of engineers and constructors in machine engineering and weapon systems.
\end{abstract}

Keywords: heavy weapons, heavy machine guns, mechanism, CAD software, geometric design, computer modeling, simulation, stress-strain

\section{Introduction}

The design of elements and mechanism for modern small arms systems is largely determined by their general purpose and specific requirements. The existence and implementation of modern CAD/CAM systems allows for the automation of processes, related to the modeling and manufacture of elements and mechanisms for small arms and light weapons. CAD / CAM systems also provide quick and accurate simulation for interacting parts and surfaces for a given mechanism and strength analysis for specific elements and units. The abovementioned greatly lowers the cost of parts while also optimizing the time invested in - modeling, designing, testing, documenting, and manufacturing including the optimization of existing models. This paper outlines the benefits of using CAD/CAM systems for the design of weapons systems. The sequence of the simulation for strength calculations for elements of the HCBT 12.7 (NSV Heavy machine-gun) in particular the sear from the trigger mechanism is also presented in the paper.

2. Applicability of CAD/CAM/CAE systems in the development and strength testing of mechanisms for light weapons and small arms.

Systems for automated design occupy an exceptional place among computer applications, as they are industrial technologies that directly affect material manufacturing.

The application of modern CAD / CAM systems includes three-dimensional modeling of individual parts, mechanisms and machines incorporating a large number of high complexity parts, from which the graphical part of the design documentation is drawn. Including - drawings (CAD); for engineering calculations and analysis (CAE); for rapid prototyping (Rapid Prototyping-RP); for manufacturing technological planning (CAP); for the preparation of control programs for $\mathrm{NC}$ machines that are capable of manufacturing 
products of different complexity (CAM). As well as for overall design and engineering data management (PDM) and documents (EDM) of a company [1].

Strength and kinematic calculations of parts with the help of CAD systems

Strength and kinematic calculations of weapon components using CAD systems are performed automatically when certain output parameters are set. The results that are required for element construction with multiple contact surfaces, such as the sear of the trigger mechanism, are displayed immediately.

Motion simulation with the help of modules in CAD / CAM / CAE systems.

For the motion simulation, the combined interaction of the coupled lever systems and spring mechanisms including the movement in the trigger mechanism is simulated. From which point the operation principles of the trigger mechanism are followed and conclusions are drawn for the respective jamming limits, collisions, tolerances, etc.

Simulation and strength calculations (stress-strain) for elements of the trigger mechanism of the HCBT (NSV machine gun) system.

Weapon systems that use the energy of high-pressure gas produced by combustion of propellant for the operation of their parts and mechanisms need to account for the strength characteristics of each separate element. In the reviewed system, when a shot is fired, a combination of high temperature gas and high pressure build up in the barrel bore. Passing through the barrel and the gas ports they actuate the components of the system, such gasses apply pressure on moving parts and pass their energy onto them [3] (from chemical energy to gas - to kinetic energy of moving parts). Geometrical CAD modeling

Geometric CAD modeling allows for the creation of elements and mechanisms, regardless of their complexity, as well as their stress-strain testing in a simulated virtual environment before they are manufactured [2]. This is a huge advantage for the production cycle and economically saving trump that should not be ignored.

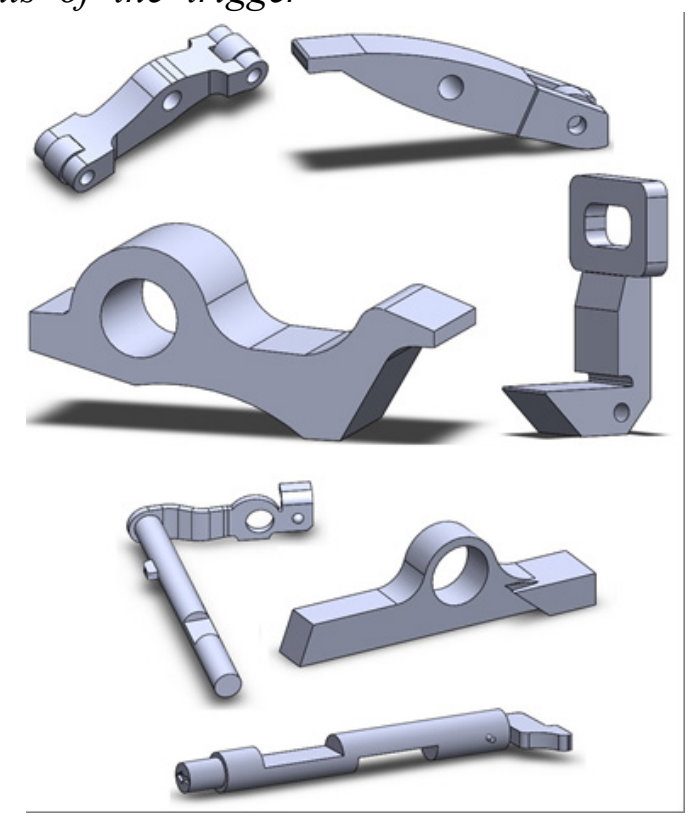

Figure 1: CAD models for the elements of the trigger mechanism for the heavy machine gun HCBT 12.7

3. Stress-strain simulation and modeling of the elements of the trigger mechanism. This paper presents an example for the modeling and stress-strain simulation of the stopping element of the bolt carrier for the HCBT $12.7 \mathrm{~mm}$ weapon system. The model 
is simulated both as a separate part and as part of an assembly after some force is applied on the right contact surface.

The steps for strength calculation and the action sequencing are outlined below. Each of the steps during the simulation and modeling can be performed in more than one way, depending on the perspective of the constructor.

The sear mechanism reviewed in the example is twisted upon impact with the bolt carrier and acts to cut off the axis on which it is secured [4]. Using the simulation software, we can identify and track these processes and analyze the results.

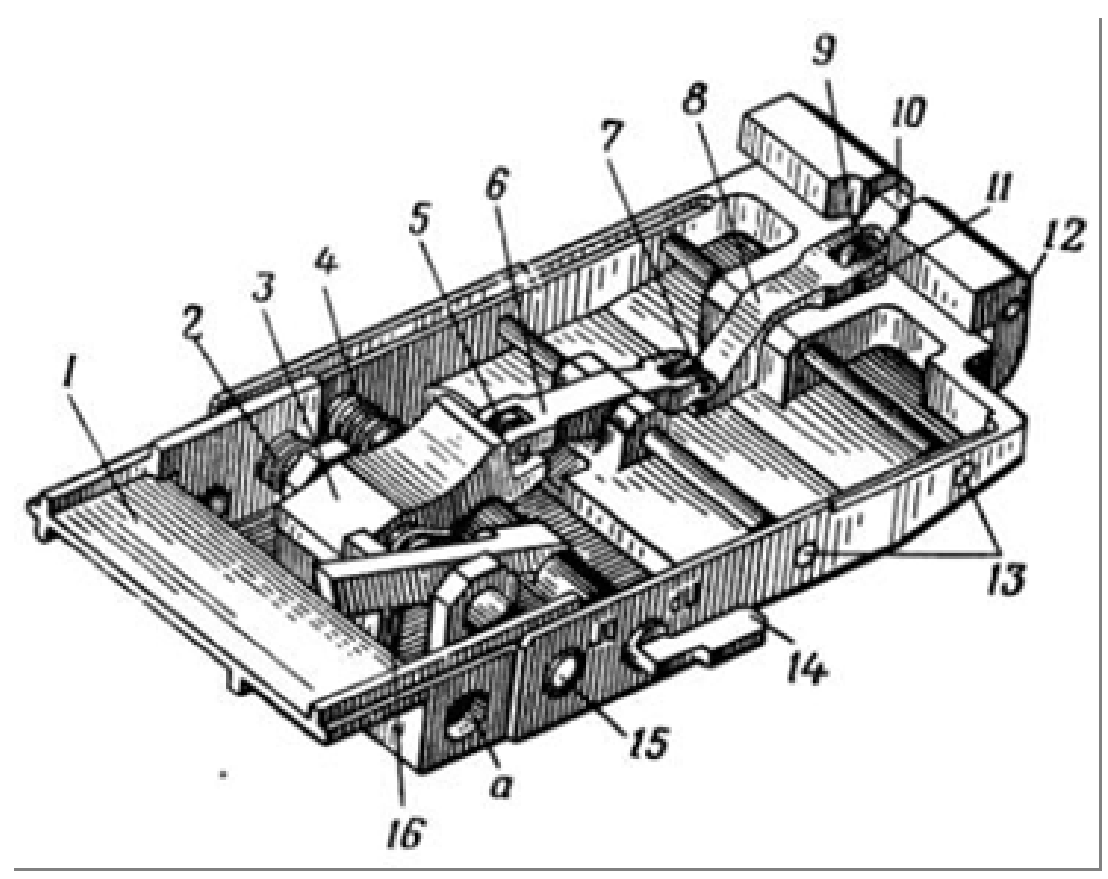

Figure 2: Three-dimensional sketching of the body and internal elements of the trigger mechanism [2] 1 -trigger mechanism body; 2 -sear spring; 3 -sear; 4-safety spring; 5, 9 -rollers; 6 -sear lever; 7 -roller axles; 8 - lever pusher; 10 - trigger; 11, 12-pusher and trigger axis; 13 -axes of the mechanisms; 14 - safety; 15 -sear axis; 16 -bolt carrier sear; a -opening of the locking lever of the bolt carrier

The main function of the trigger mechanism is to restrict or allow the movement of the bolt carrier group when the trigger is pulled, and hold the bolt carrier in place when the trigger is released. Another faction of the trigger mechanism is putting the system on safe with the help of the safety lever. The need for reliability is the main goal of this design. The reliable function of the sear is of great importance because the force it is required to withstand comes directly from the gases accumulated by firing that force back the recoil spring and the bolt carrier.

For the purpose of the paper the engineering automation product SolidWorks provides and overview of the working principles of mechanisms with great ease and precision. Parts stress test can be accessed through the SimulationXpress port by adding it as an add-on [5]. 


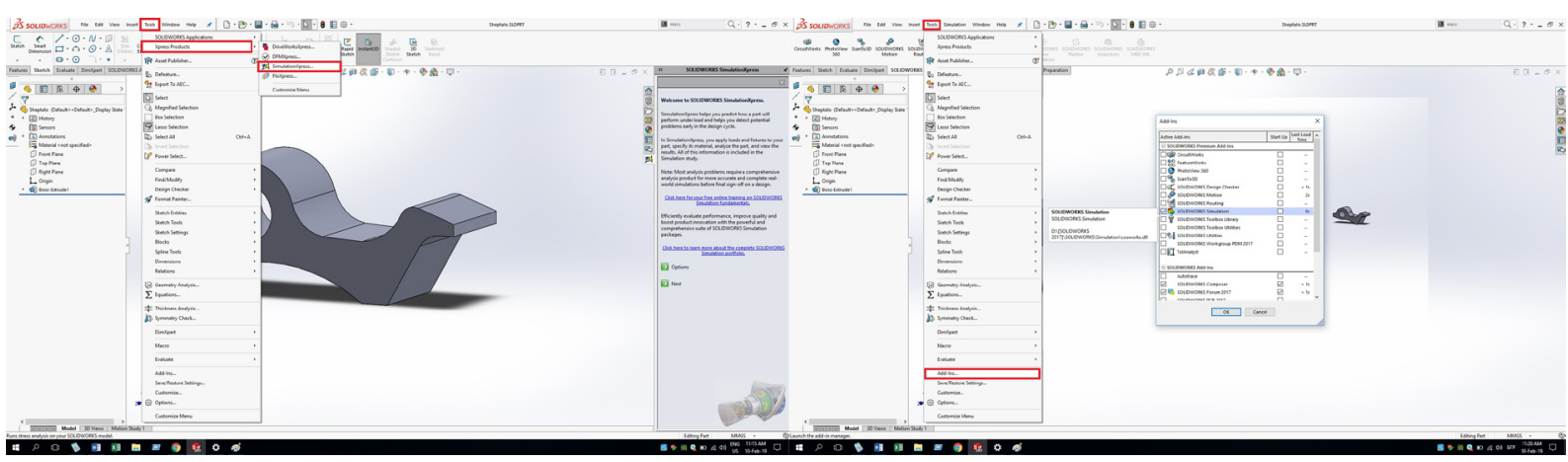

Figure 3: Starting SimulationXpress and preparing the stress-strain simulation.

With the help of the software we can determine the action, movement and functionality of the elements in real-time. Some of the sample strength calculations and operations we can highlight are:

1. The durability of the sear against a twisting motion after hitting the bolt carrier:
This stage of the research is a top priority for achieving system reliability, since the operation of the bolt carrier is directly related to the position of the sear.

Selection of the material for the sear and placing the detail in a fixed position (Figure 4)
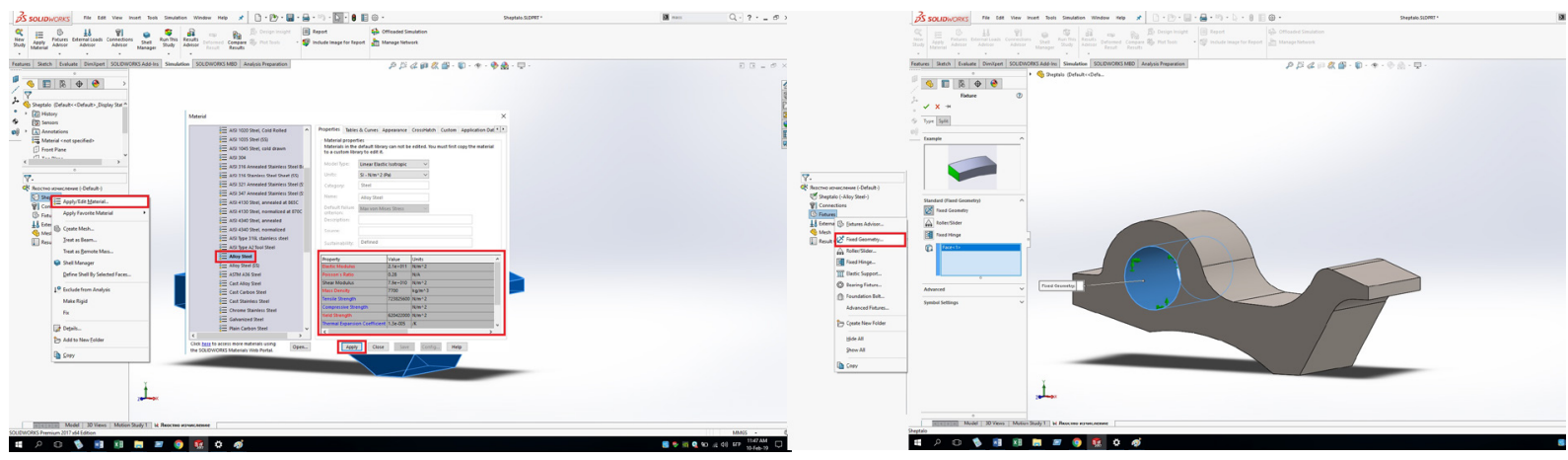

Figure 4: Selection of the material and placing the detail in a fixed position for the strength test.

The next stage is choosing an area where pressure is applies by the force of impact. Here we simulate an impact with a

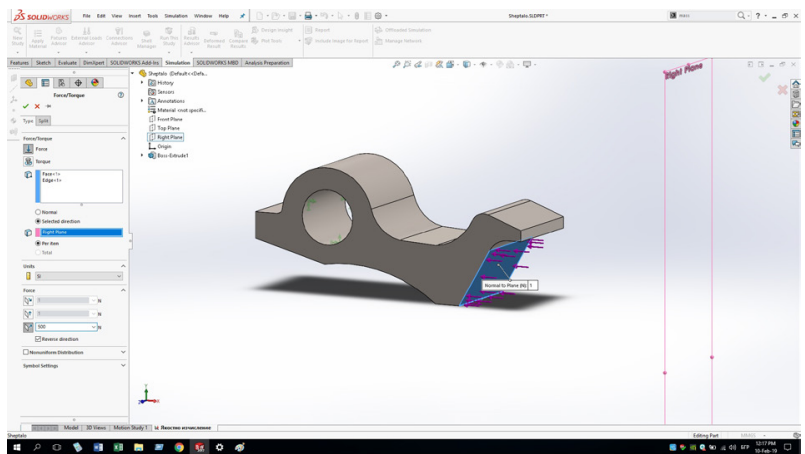

force of $50 \mathrm{~N}$ and $500 \mathrm{~N}$ to check the behavior of the mechanism in extreme load situations. (Figure 5)

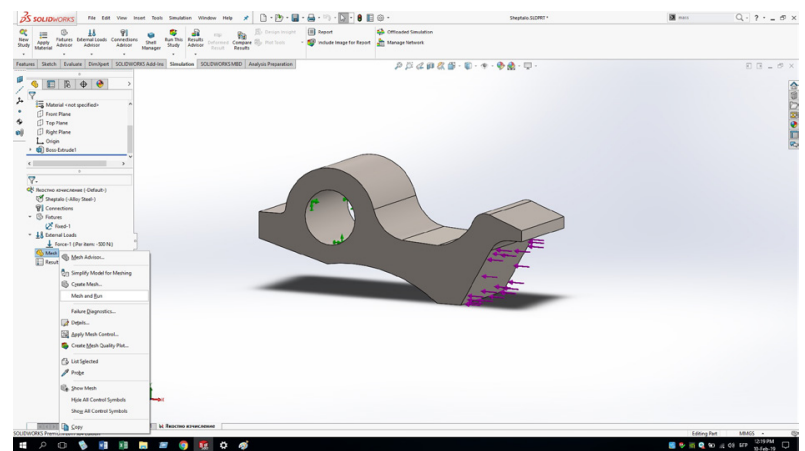

Figure 5: Choosing an area where pressure is applies by the force of impact 
After the simulation is completed (Figure 6) we can analyze the following - after a hit with force of $50 \mathrm{~N}$ and $500 \mathrm{~N}$ on the set surface the critical cross section of the sear (colored in red) shows the possible part failure. As a result, from being hit with the

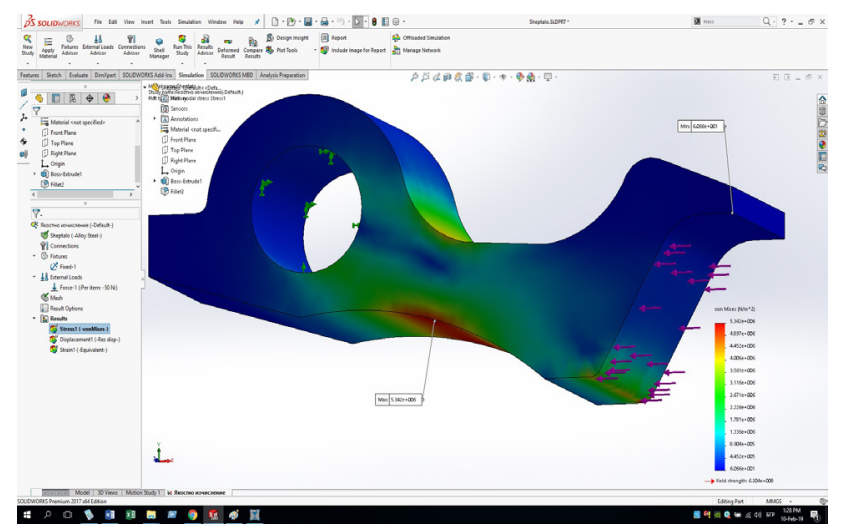

bolt carrier the sear is subjected to twisting and crushing forces in the area where the body of the part is most narrow. The areas colored in blue are the least stressed and can be modified in order to save material if the application of the element allows it.

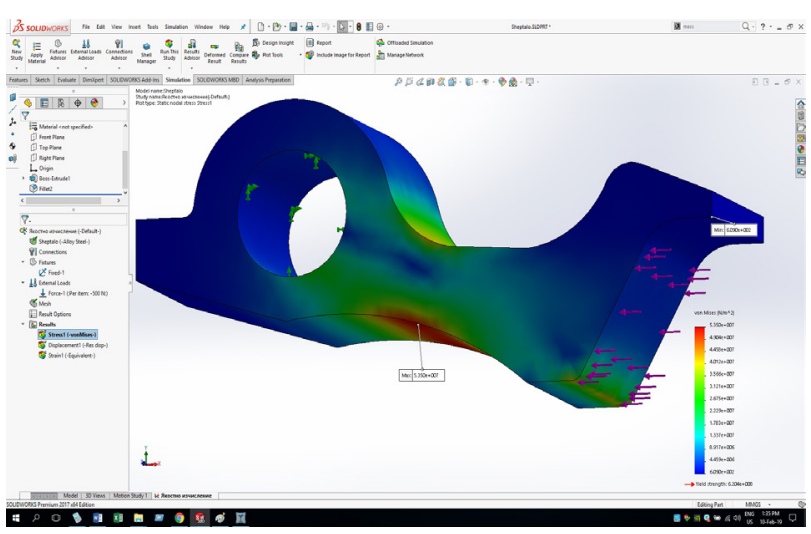

Figure 6: Carrying out the stress simulation with a hit of $50 \mathrm{~N}$ (left) and $500 \mathrm{~N}$ (right)

The presented example is an isolated strength test of an element. We can analyze the same in a different scenario.

2. Sear resistance to twisting and distortion after being hit by the bolt carrier group in an assembly with the sear's axis:

Research at this stage will highlight how the energy of the impact will spread through other key elements of the trigger mechanism - the axis of the sear. This mechanism is subjected to shearing / cutting from the oscillating opening of the sear after being hit by the bolt carrier group. (Figure 7)

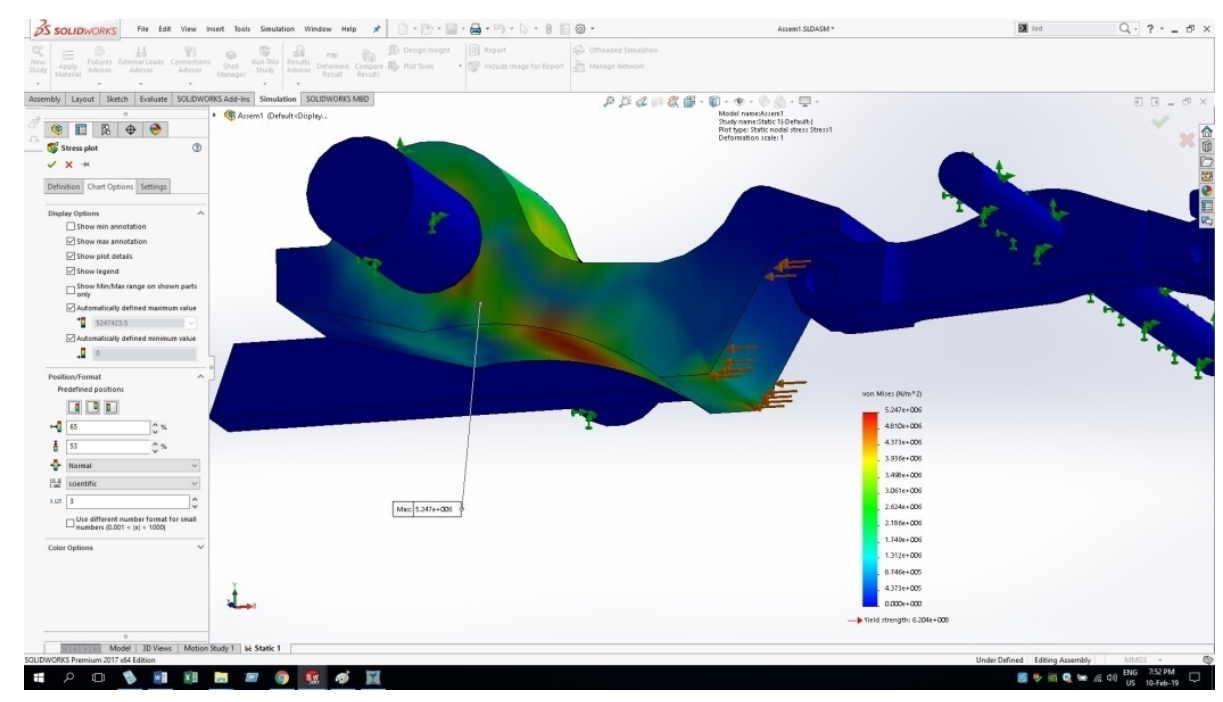

Figure 7: Strength simulation of the sear and sear axis after impact on a predetermined surface

After the simulation has been carried out (Figure 7) we can analyze the followingafter an impact with a force of $50 \mathrm{~N}$ on the predetermined surface again we observe the critical section of the element in the narrowest section. However, in this example part of the energy is scattered along the oscillating opening on the axis of the sear.

If we compare the results of Figure 6 and 
Figure 7 we can clearly determine the amount of energy that has been dissipated, due to the addition of additional elements to the strength calculation on the scale of the von Mises module.

\section{Conclusion}

This paper present the prospect for simulation and geometrical modeling of parts and mechanism of weapon systems as well as their strength testing in particularelements of the trigger mechanism (sear and sear axis) of the HCBT 12.7 weapon system. The advantages when using CAD systems for modeling and strength calculations are reviewed and the mean of simulation in a virtual reality are presented. With the help of automation products like SolidWorks, we are presented with the capability to eliminate collisions, discrepancies, errors and misalignments during the design of the mechanisms, which is a huge advantage, both economically and from a production standpoint. Furthermore, with the powerful SimulationXpress simulation software, we are able to provide the robust features of the parts in a virtual environment, which saves us time and money.

\section{References}

[1] Hristov H. A., Tsonev Ts. G., Izpolzvane na uchebno-prakticheskite mini v obuchenieto, Nauchna sesia 2011 Sbornik nauchni trudove - chast I., pp. 253, Shumen, Bulgaria, ISSN 1313-7433, 2012.

[2] Lambeva M., Hristozov I., „Prilozhenie na transformatsiyata na modeli za integrirane na informatsionni sistemi“, Godishnik na Voenna akademia „G. S. Rakovski” Fakultet „Komandno-shtaben”, Voenna akademia „G. S. Rakovski”, Sofia, 2013, s.207 - 213, ISSN 1312-2991

[3] Petrova Teodora, Petrov Zhivo, Alternative Approaches for Long-Term Defence Planning, Proceedings of SOCIOINT 2020-7th International Conference on Advances in Education and Social Sciences, 20-22 January, 2020-Dubai, U.A.E., pp. 818-825, ISBN 978-60582433-8-5

[4] Petrova Teodora, Petrov Zhivo, (2020), Long Term Development Perspectives for UAV Potential, Proceedings of SOCIOINT 2019-7th International Conference on Advances in Education and Social Sciences, 20-22 January, 2020-Dubai, U.A.E., pp. 802-810, ISBN 978-605-82433-8-5

[5] Stamen I. Antonov, Tsonio G. Tsonev, "Possibilities for automation of designing elements of small arms using CAD/CAM/CAE systems", Collection of papers, p.p. 319-324, "Vasil Levski" National Military University - Artillery, Air Defense and CIS Faculty, Shumen, Bulgaria, 2016, ISSN 2367-7902

[6] Vasilev V.M., Izpolzvane na metoda na dopiratelnite ploskosti pri modelirane na difuzno preotrazhenie, Sbornik nauchni trudove, chast I ot nauchna konferentsia na Fakultet "A, PVO and KIS", Shumen, Bulgaria, 2006g., str. 254 - 260, ISBN 978-954-9681-19-2

[7] Vasilev V.M., "Stochastic model of complex ISAR signals and spatial correlation image reconstruction procedure", The 32nd International scientific conference of the military technical academy "Modern technologies in the 21st century", Buharest 2007, ISBN 978973-640-127-5 